IRA-International Journal of Education \& Multidisciplinary Studies ISSN 2455-2526; Vol.05, Issue 03 (2016)

Pg. no. 196-202

Institute of Research Advances

http://research-advances.org/index.php/IJEMS

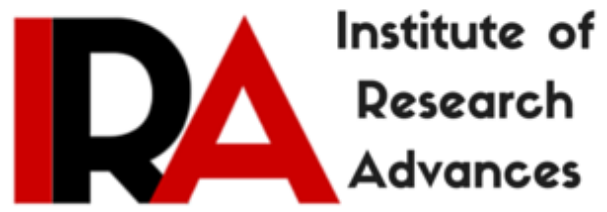

\title{
General Mental Alertness in Visually Challenged and Sighted Students
}

Dr. Rekha Rani

Post Doctoral Fellow, Department of Education

Aligarh Muslim University, Aligarh (UP), India.

Type of Review: Peer Reviewed.

DOI: http://dx.doi.org/10.21013/jems.v5.n3.p8

\section{How to cite this paper:}

Rani, R. (2016). General Mental Alertness in Visually Challenged and Sighted Students. IRA International Journal of Education and Multidisciplinary Studies (ISSN 2455-2526), 5(3), 196-202. doi:http://dx.doi.org/10.21013/jems.v5.n3.p8

(C) Institute of Research Advances

(cc) EY-NC

This work is licensed under a Creative Commons Attribution-Non Commercial 4.0 International License subject to proper citation to the publication source of the work.

Disclaimer: The scholarly papers as reviewed and published by the Institute of Research Advances (IRA) are the views and opinions of their respective authors and are not the views or opinions of the IRA. The IRA disclaims of any harm or loss caused due to the published content to any party. 


\section{ABSTRACT}

The present study has been conducted to study the impact of vision on mental alertness. The visually challenged and sighted students were compared on general mental alertness. The two groups (visually challenged \& sighted) were compared on quantitative ( $Q$ score) and linguistic scores ( $L$ score) of mental alertness. Further the impact of gender was also studied on general mental alertness of both the groups. A sample of 117 (45 visually challenged and 72 sighted) students from Aligarh city was selected for the study. The general mental alertness test developed by Kumari \& Bano (2013) was administered to the students. The findings of the study reveal that the visually challenged differ significantly on general mental alertness from their sighted counterparts. The two groups differ on quantitative scores while on linguistic scores no significant difference was found. Moreover gender has no significant impact on the mental alertness of both the groups.

\section{INTRODUCTION}

Alertness is the state of paying close and continuous attention, being watchful and prompt to meet danger or emergency and being quick to perceive and act. Mental alertness refers to the performance of a system. Some people perform better than others in solving problems, comprehending events \& messages and learning. Thus, the alertness means keenly watchfulness ready for sudden action. According to Thurston(1952) 'Mental alertness refers to the kind of thinking, flexibility and versatility an individual possesses that makes it possible for him to adjust to new situation. Mental alertness is any function pertaining to the mind, such as awareness, perception, imagination, and reasoning (Srivastava, 1986). Thus, mental alertness is the mental characteristic of a person who is quick and alert to the problems. Mehta (1993) studied a cross cultural illusion in relation to general mental alertness and academic performance. A sample of 1000 students was taken for the study. The study revealed that the female students have high mental alertness than their male counterparts. Moreover science students were found to be mentally more alert than arts students. Cunningham (2009) investigated the comparability level of the Thurston test of Mental Alertness (TMA) when administered in both a paper \& pencil format and an online, web-enabled format. The obtained results supported the notion that students would obtain similar scores on the internet version of the TMA when compared to the scores they produced on paper \& pencil format.

Vision is a powerful sensory modality which integrates and co-ordinates the information provided by other senses, allowing the features of the external world to be consolidated as a unified experience (Rock, 1985). The status of mental alertness is affected by the vision as cognitive maps enable us to perceive objects in their totality and in context. Vision facilitates the production of mental images quickly condensing information into a single and meaningful snapshot (Thinus-Blanc \& Gaunet, 1997). The behaviour of visually impaired children is shaped by the limitations of their visual input. This alters their perceptions of the environment, their own understandings of cause and effect and the relationships between people and/or objects (Jan et al, 1977). Van der Kolk (1977) studied the relationship between intelligence and various types and characteristics of visual impairment (congenital, adventitious, degree of vision, attendance to private or public school, level of education, family and social status). He found that the sighted and the blind were similar in IQ scores. Ittyerah and Samarapungavan (1989) found that cognitive development in the blind is not identical to that in the sighted group. Performance deficits are the result of both, long term absence of experiences and absence of direct or immediate visual information about the stimulus at hand. Jan et al. (1990) revealed that visual impairment affects the total process of gathering and exchanging information and the effect is noticeable not only in motor skills, but also in cognition, language development and social skills. Warren (1994) argued that blind children show more delayed cognitive development as compared to sighted children. Morrongiello et al. (1994) found no differences between the sighted and the blind in their ability to identify everyday objects as well as miniaturized and oversized versions of these objects. Hatwell (2003) revealed that the lack of vision leads 
to a curtailment of interaction with both objects and people in the environment. It reduces the quantity and quality of data reaching the individual and eventually leads to problems in logical reasoning. Puche et al. (2007) concluded that the format of the task influences performance more than the child's visual ability. Pinquart \& Pfeiffer (2011) revealed that visually impaired people showed a strong decline of visionspecific psychological well-being. Marjolein et al. (2014) concluded that children with ocular plus congenital blindness were delayed in development of theory of mind when compared with their sighted peers. Rani (2016) pointed out the need for development of standardized psychometric test materials to assess the capabilities of visually challenged, as majority of tests developed for the sighted population have been adapted by the researchers to use with visually challenged.

A perusal of research in the field reveals that no matter how different visually challenged individuals may be, they still maintain many characteristics in common with the rest of the population. The brain mechanism of visually challenged individuals is fully intact and comparable to normal children but the vision status affects the total process of gathering and exchanging information. Moreover, the nature of the information, format of the task and type of opportunities given to visually challenged individuals also affects their performance. In the present study, an attempt has been made to study the impact of vision on mental alertness. The investigator aimed to assess the level of mental alertness in the visually challenged students as compare to their sighted counterparts.

\section{Objectives of the Study:}

1. To compare visually challenged and sighted students on the general mental alertness.

2. To study the significance of difference between visually challenged and sighted students on the quantitative scores and linguistic scores of mental alertness.

3. To study the effect of gender on the mental alertness of visually challenged and sighted students.

\section{Hypotheses:}

1. Visually challenged and sighted students do not differ significantly on the general mental alertness.

2. There exists no significant difference between visually challenged and sighted students on the quantitative scores and linguistic scores of mental alertness.

3. Gender has no significant effect on the mental alertness of visually challenged and sighted students.

\section{Methodology:}

\section{Population and sample:}

All the visually challenged and sighted students studying in secondary schools of age group 13-18 years comprised the population of the study. A sample of 117 (45 visually challenged and 72 sighted) students from Aligarh city was selected for the study.

\section{Tool Used:}

The general mental alertness test developed by Kumari \& Bano (2013) was used for the study. The test consisted of 44 mutiple-choice type items based on reasoning, definitions, number series and same \& opposites. There were two types of series of scores in the present test. The arithmetic reasoning and number series form the 'Q' score (Quantitative Score) definition and same-opposites form ' $L$ ' scores (Linguistic Score). For each correct response one mark and for wrong response zero was given. The test was valid and reliable (0.74). 


\section{Data Processing:}

Statistical measures of central tendency and t-test were employed to find out the significance of difference between the mean scores obtained by the students under study.

\section{Results and Discussion:}

Results of the test of significance of difference between mean scores of two samples i.e. visually challenged and sighted students on the variable of mental alertness are presented below.

Table:1

Comparison of Visually Challenged and Sighted Students

on different dimensions of General Mental Alertness

\begin{tabular}{|c|c|c|c|c|c|c|}
\hline \multirow[t]{2}{*}{$\begin{array}{l}\text { Dimensions of General } \\
\text { Mental Alertness }\end{array}$} & \multicolumn{2}{|c|}{$\begin{array}{l}\text { Visually Challenged } \\
\text { Students } \\
(\mathrm{N}=45)\end{array}$} & \multicolumn{2}{|c|}{$\begin{array}{l}\text { Sighted Students } \\
(\mathrm{N}=72)\end{array}$} & \multirow[t]{2}{*}{ 't' Value } & \multirow[t]{2}{*}{$\begin{array}{l}\text { Level of } \\
\text { Significance }\end{array}$} \\
\hline & Mean & SD & Mean & SD & & \\
\hline $\begin{array}{l}\text { 1) Arithmetic } \\
\text { Reasoning }\end{array}$ & 4.88 & 2.38 & 5.98 & 2.55 & 2.31 & .01 level \\
\hline 2) Definition & 5.11 & 2.01 & 5.79 & 2.27 & 1.64 & $\begin{array}{l}\text { Not } \\
\text { significant }\end{array}$ \\
\hline 3) Number Series & 4.98 & 2.36 & 5.94 & 2.79 & 1.93 & .05 level \\
\hline 4) Same-Opposites & 5.31 & 1.86 & 5.69 & 2.49 & 0.89 & $\begin{array}{l}\text { Not } \\
\text { significant }\end{array}$ \\
\hline Total & 20.28 & 5.99 & 23.41 & 8.22 & 2.21 & .01 level \\
\hline
\end{tabular}

The table 1 depicts that the mean score of sighted students is higher (23.41) than their visually challenged counterparts (20.28) on the general mental alertness. The difference between the mean scores is significant (2.21) at .01 level indicating that sighted students are mentally more alert than visually challenged. The mean scores on different dimensions of general mental alertness signify that sighted students are significantly better on arithmetic reasoning and number series dimensions while on definition and same-opposite dimensions both sighted and visually challenged do not differ significantly. However the mean scores of sighted students are higher as compare to their visually challenged counterparts on both the dimensions.

The result obtained may be the effect of vision loss due to which a visually impaired individual is unable to gather, exchange and produce meaningful information. The lack of vision may leads to a restriction of interaction with both objects and people in the environment. It reduces the quantity and quality of data reaching the individual and eventually leads to problems in logical reasoning (Hatwell, 2003).

The results of the present study are in coordination with the findings of the study conducted by Warren, 1994; Marjolein et al. ,2014 who revealed that blind children show more delayed cognitive development 
as compared to sighted children while Puche et al. (2007) pointed out that, the type of opportunities given to explore the environment and the format of the task influences performance more than the child's visual ability. However, investigator found not a single study to compare sighted and visually challenged students on the general mental alertness.

Table:2

Comparison of Visually Challenged and Sighted Students on ' $Q$ ' and ' $L$ ' Scores of General Mental Alertness

\begin{tabular}{|c|l|l|l|l|l|l|}
\hline $\begin{array}{l}\text { Type of Scores on } \\
\text { GMAT }\end{array}$ & $\begin{array}{l}\text { Visually } \\
\text { Challenged } \\
\text { Students } \\
(\mathrm{N}=45)\end{array}$ & \multicolumn{2}{l|}{$\begin{array}{l}\text { Sighted Students } \\
(\mathrm{N}=72)\end{array}$} & 't' Value & $\begin{array}{l}\text { Level } \\
\text { Significance }\end{array}$ \\
\cline { 2 - 5 } & Mean & SD & Mean & SD & & \\
\hline 1) 'Q' Scores & 9.86 & 4.38 & 11.93 & 5.13 & 2.23 & .01 \\
\hline 2) 'L' Scores & 10.42 & 3.29 & 11.48 & 4.33 & 1.41 & Not Significant \\
\hline
\end{tabular}

The above table 2 shows that visually challenged and sighted students differ significantly on quantitative scores i.e. Q scores. The mean score of visually challenged is 9.86 while the mean score of sighted students is 11.93 , the 't' value (2.23) obtained is significant at .01 level. However both the groups have no significant difference on linguistic score i.e. L scores, the 't' value (1.41) found to be insignificant. The above result may be due to the lack of opportunities given to visually challenged students to handle the problems related to mathematics and they just study languages and other such subjects at school level. Moreover the testing material used in the present study is not in tactile format suitable for visually challenged, it may affect their comprehension of the related problem. The review of the literature reveals that no such study has been conducted so far as the knowledge of the investigator is concerned.

Table: 3

Effect of Gender on General Mental Alertness

Of Visually Challenged and Sighted Students

\begin{tabular}{|c|c|c|c|c|c|c|c|}
\hline \multicolumn{4}{|c|}{ Visually Challenged Students } & \multicolumn{3}{|c|}{ Sighted Students } & \multirow[t]{2}{*}{ Level of Significance } \\
\hline Gender & Mean & SD & 't' value & Mean & SD & 't' value & \\
\hline Male & 19.81 & 6.69 & \multirow{2}{*}{0.64} & 22.84 & 8.79 & \multirow{2}{*}{0.76} & \multirow{2}{*}{ Not significant } \\
\hline Female & 21.00 & 4.85 & & 24.37 & 7.22 & & \\
\hline
\end{tabular}


Table 3 reveals that the mean score of female visually challenged (21.00) is higher than their male counterparts (19.81). The ' $t$ ' value thus obtained (0.64) is not significant even at .05 level. This result leads the investigator to conclude that gender has no significant impact on the general mental alertness of visually challenged students. The result of sighted students is also in co-ordination with the visually challenged indicating no significant difference between male and female students on general mental alertness. However the mean score of female students (24.37) is higher than their male counterparts (22.84) as in case of visually challenged. The result is corroborated with the findings of the study conducted by Mehta (1993) who revealed that female students have high mental alertness than male students.

\section{Conclusion and Suggestions:}

The findings of the study reveal that visually challenged showed a decline in general mental alertness as compare to the sighted. The behaviour of visually impaired children is shaped by the limitations of their visual input. This alters their perceptions of the environment, their own understandings of cause and effect and the relationships between people and/or objects. Their behaviour may well be their normal reaction to different information that they receive, rather than a deviation (Jan et al., 1977). However, vision loss does not automatically lowers mental ability but absence of direct or immediate visual information about the stimulus at hand, lack of opportunities given to them and limited experiences to explore the environment may be the reason of delayed integrating and coordinating information, comprehending events \& messages and learning which may lead to decline in general mental alertness in visually challenged individuals.

Since, due to the deprivation of sense of vision, there is significant reduction in the range and variety of experiences therefore particular care should be given while comparing the visually impaired with that of the sighted considering many of the tasks designed to test knowledge and assess intelligence tend to rely heavily on vision. The majority of experiences that a visually challenged person has are audio and tactile therefore it is suggested that suitable adaptations and accommodations should be applied as needed by visually challenged during test by probing possible ways of touching, making contacts and exploring, in which skin, muscles, and joints work together to collect reliable information. Moreover, the tactile material may built up their confidence to comprehend the problem by their own experience of manipulating, integrating and coordinating the given information which may lead to develop their mental abilities and boost mental alertness.

\section{References:}

1. Cunningham, M.R. (2009). Comparison of a paper and pencil to a web-enabled version of the Thurston test of mental alertness (TMA). Ph.D., University of Louisville, Midwestern Psychological Asoociates, Annual Conference, Chicago.

2. Hatwell, Y. (2003). Psychologie cognitive de la cecite precoce. Paris: Dunod Editeur.

3. Ittyerah,M. and Samarapungavan,A. (1989) The performance of congenitally blind children in cognitive developmental tasks. British Journal of Developmental Psychology, 7(2): 129-139.

4. Jan, J.E., Freeman, R.D., Scott, E.P. (1977) Visual Impairment in Children and Adolescents. New York: Grune \& Stratton.

5. Jan, J.E. ; Sykanda and Groenneld (1990) Habitation and rehabilitation of visually impaired and blind children, Pediatrician, 17(3) :202-207.

6. Kumari, S. \& Bano,S. (2013) Manual for General Mental Alertness Test (GMAT) for secondary level. Rupa Psychological Centre, Varanasi.

7. Marjolein, B.S.D et al. (2014). A new look at theory of mind in children with ocular and ocular plus congenital blindness. Journal of Visual Impairment \& Blindness, 108, 17-27 Jan-Feb 2014. 
8. Mehta, S. (1993) A cross cultural study of illusion in relation to general mental alertness and academic performance (Experimental Study). Ph.D. Thesis, Psychology, Rani Durgavati Vishwavidyalaya, Jabalpur, India.

9. Pinquart, M. \& Pfeiffer, J.P. (2011) Psychological well-being in visually impaired and unimpaired individuals. British Journal of Visual Impairment. 29( 1): 27-45

10. Puche,Navarro-Rebeca;Millan,Rafael(2007) Inferential functioning in visually impaired children, Research in Developmental Disabilities: A Multidisciplinary Journal, 28(3): 249-265.

11. Rani, R. (2016) Vision Impairments and Intelligence Testing in India. Disabilities and Impairments: An Interdisciplinary Research Journal, 30(1): 51-58.

12. Rock,L. (1985) The logic of perception, MIT Press, Cambridge,Mass.

13. Schinazi,V.R.(2008) Representing space: The development, content and accuracy of mental representations by the blind and visually impaired. Ph.D. Thesis, Centre for Advanced Spatial Analysis The Bartlett School of Graduate Studies University College London.

14. Srivastava,R.P.(1986) Manual for General Mental Alertness Test., National Psychological Corporation, Agra.

15. Thinus-Blanc, C., \& Gaunet, F. (1997). Representation of space in blind persons: Vision as a spatial sense? Psychological Bulletin, 121, 20-42.

16. Thurston, L.L.(1952). Thurston test of Mental Alertness and Examiner Manual, III, University of Chicago Press, Chicago.

17. Van der Kolk, C. J. (1977). Intelligence testing for visually impaired persons. Journal of Visual Impairment and Blindness, 71, 158-163.

18. Warren, D. H. (1994) Blindness and Children: An Individual Differences Approach, Cambridge University Press, Cambridge. 